REGARDS

SUR L'ECONOMIE ALLEMANDE

BULLETIN ECONOMIQUE DU CIRAC
Regards sur l'économie allemande

Bulletin économique du CIRAC

$107 \mid 2012$

Varia

\title{
Compétitivité du Mittelstand
}

HENARD J., L'Allemagne : un modèle, mais pour qui ? / KOHLER D., WEISZ J.-D., Pour un nouveau regard sur le Mittelstand

\section{(2) OpenEdition}

Journals

Édition électronique

URL : http://journals.openedition.org/rea/4502

DOI : $10.4000 /$ rea.4502

ISBN : 978-2-8218-1424-0

ISSN : 1965-0787

Éditeur

CIRAC

Édition imprimée

Date de publication : 20 décembre 2012

ISSN : 1156-8992

Référence électronique

"Compétitivité du Mittelstand », Regards sur l'économie allemande [En ligne], 107 | décembre 2012, mis en ligne le 14 janvier 2013, consulté le 22 septembre 2020. URL : http://journals.openedition.org/rea/ 4502 ; DOI : https://doi.org/10.4000/rea.4502

Ce document a été généré automatiquement le 22 septembre 2020.

(c) CIRAC 


\section{Compétitivité du Mittelstand}

HENARD J., L'Allemagne : un modèle, mais pour qui ? / KOHLER D., WEISZ J.-D., Pour un nouveau regard sur le Mittelstand

\section{RÉFÉRENCE}

HENARD J., L'Allemagne : un modèle, mais pour qui ? La Fabrique de l'industrie, Presse des MINES, Paris, 2012, 54 p.

KOHLER D., WEISZ J.-D., Pour un nouveau regard sur le Mittelstand, Rapport au Fonds stratégique d'investissement, La documentation française, Paris, 2012, 129 p.

1 Exit, le «modèle allemand "? Si dans le débat public français, le terme de "modèle » accolé à «Allemagne » est désormais politiquement incorrect, rien n'interdit de se pencher sur la normalité de notre partenaire et le 'secret' de sa compétitivité. Voici deux ouvrages solides qui rompent avec une série d'idées reçues sur ces fameuses ETI dont rêve la France ou cet " écosystème » à la fois industriel et social qui fascine tant. Ces ETI allemandes n'existent que dans un imaginaire français qui a du mal à concevoir le fonctionnement du travail au quotidien de ces fourmis qui composent en réalité le Mittelstand; le rapport de KOHLER et al. passe entre autres en revue ce qui fait "l'ADN" de ces fameuses PME industrielles - résumant sous ce terme à la mode les facteurs structurels et culturels qui font la compétitivité de l'approche entrepreneuriale allemande. Quant au "modèle » industriel, il ne repose sur aucun 'secret de fabrique', mais tout simplement sur un grand "professionalisme", comme le souligne Louis Gallois dans sa préface à l'analyse de J. HÉNARD. Cette dernière nous livre un tour d'horizon détaillé et très précieux, car réaliste et pragmatique, de ce que recouvre en réalité ce qu'on cherche à traduire par ADN (vision statique) : "un modèle de méthode » (vision dynamique, à l'opposé). Où l'on s'aperçoit aussi que, finalement, le patient travail de fourmi et le professionalisme du CIRAC dans l'information qu'il produit sur les facteurs systémiques au fondement $d u$ «modèle » économique et social allemand portent leurs fruits, du moins dans la société civile... (ib) 